INEL-95/0384

\title{
OPPORTUNITIES FOR MIXED OXIDE FUEL TESTING IN THE ADVANCED TEST REACTOR TO SUPPORT PLUTONIUM DISPOSITION
}

\author{
by \\ William K. Terry, John M. Ryskamp, James W. Sterbentz, \\ Gray S. Chang, Richard G. Ambrosek, and \\ Steven L. Hayes (Argonne National Laboratory-West)
}

August 1995

\section{DISCLAIMER}

This report was prepared as an account of work sponsored by an agency of the United States Government. Neither the United States Government nor any agency thereof, nor any of their employees, makes any warranty, express or implied, or assumes any legal liability or responsibility for the accuracy, completeness, or usefulness of any information, apparatus, product, or process disclosed, or represents that its use would not infringe privately owned rights. Reference herein to any specific commercial product, process, or service by trade name, trademark, manufacturer, or otherwise does not necessarily constitute or imply its endorsement, recommendation, or favoring by the United States Government or any agency thereof. The views and opinions of authors expressed herein do not necessarily state or reflect those of the United States Government or any agency thereof.

\author{
Lockheed Martin Idaho Technologies Company \\ Idaho National Engineering Laboratory \\ P. O. Box 1625 \\ Idaho Falls, ID 83415-3885
}




\section{DISCLAIMER}

Portions of this document may be illegible in electronic image products. Images are produced from the best available original document. 


\section{SUMMARY}

The safety of people throughout the world is seriously threatened by nuclear weapons stockpiles and by weapons-grade plutonium (WGPu) from nuclear weapons dismantled in arms-reduction programs. An intense worldwide effort is now under way to find means of reducing this danger. One of the most attractive solutions would be to use WGPu as fuel in existing light water reactors (LWRs) in the form of mixed oxide (MOX) fuel - i.e., plutonia $\left(\mathrm{PuO}_{2}\right)$ mixed with urania $\left(\mathrm{UO}_{2}\right)$. Before U.S. reactors could be used for this purpose, their operating licenses would have to be amended.

Numerous technical issues must be resolved before LWR operating licenses can be amended to allow the use of MOX fuel. These issues include the following:

- MOX fuel fabrication process verification

- Whether and how to use burnable poisons to depress MOX fuel initial reactivity, which is higher than that of urania

- The effects of WGPu isotopic composition

- The feasibility of loading MOX fuel with plutonia content up to 7\% by weight

- The effects of americium and gallium in WGPu

- $\quad$ Fission gas release from MOX fuel pellets made from WGPu

- $\quad$ Fuel/cladding gap closure

- The effects of power cycling and off-normal events on fuel integrity

- Development of radial distributions of burnup and fission products

- $\quad$ Power spiking near the interfaces of MOX and urania fuel assemblies

- Fuel performance code validation.

The Advanced Test Reactor (ATR) at the Idaho National Engineering Laboratory possesses many advantages for performing tests to resolve most of the issues identified above. It has ample core test volume, high neutron flux, test loops with cooling systems independent of the core coolant, and extensive support facilities. However, to be useful for MOX fuel testing, 
the ATR must be able to deliver a neutron flux of appropriate intensity and energy distribution to the MOX test specimens while simultaneously accommodating test requirements for other programs.

We have performed calculations to show that the use of hafnium shrouds can produce spectrum adjustments that will bring the flux spectrum in ATR test loops into a good approximation to the spectrum anticipated in a commercial LWR containing MOX fuel while allowing operation of the test fuel assemblies near their optimum values of linear heat generation rate. The ATR would be a nearly ideal test bed for developing data needed to support applications to license LWRs for operation with MOX fuel made from weaponsgrade plutonium.

The requirements for planning and implementing a test program in the ATR have been identified.

The facilities at Argonne National Laboratory-West can meet all potential needs for pre- and post-irradiation examination that might arise in a MOX fuel qualification program. 


\section{CONTENTS}

SUMMARY $\ldots \ldots \ldots \ldots \ldots \ldots \ldots \ldots \ldots$ ii

1.0 INTRODUCTION $\ldots \ldots \ldots \ldots \ldots \ldots \ldots \ldots \ldots \ldots \ldots$

2.0 ISSUES TO BE RESOLVED BY MOX FUEL IRRADIATION TESTING . . . . . . 4

2.1 MOX Fuel Fabrication Process Verification . . . . . . . . . . . 5

2.2 Burnable Poisons . . . . . . . . . . . . . . . . . . 6

2.3 Effect of Low Pu-240 Content . . . . . . . . . . . . . . . . 6

2.4 Effect of High Plutonium Content . . . . . . . . . . . . . . 6

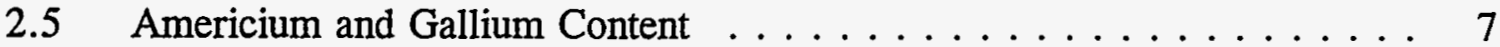

2.6 Fission Gas Release . . . . . . . . . . . . . . . . . . . . 7

$2.7 \quad$ Fuel/Cladding Gap Closure . . . . . . . . . . . . . . . . . 7

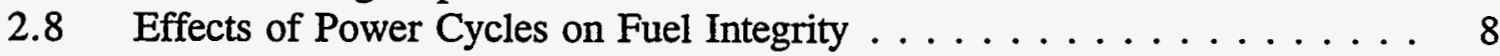

2.9 Off-Normal Events . . . . . . . . . . . . . . . . . . . 8

2.10 Radial Distribution of Burnup and Fission Products . . . . . . . . . 8

2.11 Thermohydraulic Behavior . . . . . . . . . . . . . . . 8

2.12 Power Spiking . . . . . . . . . . . . . . . . 9

2.13 Code Validation $\ldots \ldots \ldots \ldots \ldots \ldots \ldots \ldots \ldots$

3.0 THE POTENTIAL ROLE OF THE ATR IN MOX FUEL TESTING $\ldots \ldots \ldots$

4.0 CONDUCTING A TEST PROGRAM IN ATR LOOP

AND CAPSULE FACILITIES . . . . . . . . . 13

4.1 Description of Test Hardware . . . . . . . . . . . . . . 13

4.2 Specification of Requirements for Operating Conditions . . . . . . . 13

4.3 Scheduling Requirements . . . . . . . . . . . . . . . 14

4.4 Safety Considerations . . . . . . . . . . . . . . . . . . . 14

5.0 POST-IRRADIATION EXAMINATION CAPABILITIES AT ANL-W . . . . . 15

5.1 Non-destructive examinations . . . . . . . . . . . . . . . . . 15

5.2 Destructive Examinations . . . . . . . . . . . . . . . 16

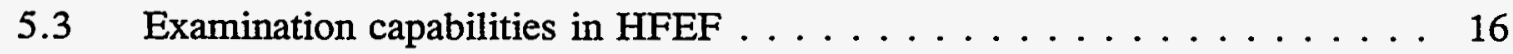

REFERENCES . . . . . . . . . . . . . . . . . . . . . 19 


\subsection{INTRODUCTION}

World security is seriously threatened by nuclear weapons stockpiles and by weapons-grade plutonium that is now accumulating from nuclear warheads being dismantled in the arms reduction programs agreed upon by the United States and the former Soviet Union. The familiar dangers posed by nuclear weapons in operational military forces will be with us for the foreseeable future; however, the arms reductions programs have introduced a new but reducible hazard. As long as weapons-grade plutonium remains in retired weapons or in a form usable in weapons, it could be obtained by terrorist groups or renegade governments and used for extortion or outright mass murder. Therefore, an intense worldwide effort is now under way to find means of making weapons-grade plutonium unavailable for use in fission weapons. As part of this effort, the National Academy of Sciences has studied a broad range of possible ways to dispose of excess weapons-grade plutonium.

The Academy's report ${ }^{1}$ provides valuable insight on the problems associated with weaponsgrade plutonium disposition and presents a well-reasoned assessment of the various disposition options. Some of the report's principal insights and conclusions serve as an appropriate foundation for this discussion of the INEL's potential role in weapons-grade plutonium disposition.

Plutonium is bred in nuclear reactors by a sequence of reactions that begins with the absorption of a neutron by a uranium-238 (U-238) nucleus. The form of plutonium that results initially from this absorption is plutonium-239 (Pu-239). Absorption of neutrons in Pu-239 produces $\mathrm{Pu}-240$, and an additional absorption produces Pu-241. Plutonium derived from the transmutation of U-238 in power reactors is called "reactor-grade" plutonium. Weapons-grade plutonium is produced in specially designed reactors in which the U-238 is irradiated for relatively brief time intervals before it is removed for extraction of plutonium. Because of the much longer residence of uranium fuel in power reactors, considerably more $\mathrm{Pu}-240$ and $\mathrm{Pu}-241$ accumulate from subsequent neutron absorptions in power reactors than in weapons-production reactors. The lower Pu-240 and Pu-241 content in weapons-grade plutonium is highly desirable for the manufacture of nuclear weapons. However, the Academy is careful to stress the fact that a highly effective fission weapon can be constructed from reactor-grade plutonium (contrary to widespread belief). Spent fuel taken from commercial power reactors therefore contains plutonium that could be extracted for nuclear weapons production by a straightforward chemical separation process.

The worldwide stock of reactor-grade plutonium in spent fuel is much larger than the stock of excess weapons-grade plutonium from the arms-reduction programs, and it is growing. Therefore, the Academy observes that it would add little to overall world security to provide protection for weapons-grade plutonium more stringent than the protection provided (by the aggregate of institutional and physical barriers) for plutonium in commercial spent fuel. The Academy proposes a "spent-fuel standard" by which to evaluate disposition options: the chosen method for long-term disposition of weapons-grade plutonium should render this material roughly as inaccessible as the plutonium in commercial spent fuel; the additional cost of making weapons-grade plutonium less accessible than this would not provide significant benefits. (However, the Academy asserts that the protection currently provided 
for plutonium in spent fuel is not adequate in the long run, and that long-term disposition of all plutonium should meet higher standards of protection than presently provided.)

The Academy finds that two of the possible disposition options seem more promising than any of the others, and that a third option, which is still in an early stage of study, may upon further investigation prove competitive with the two leaders. The first leading candidate is the use of plutonium as fuel in existing or modified reactors, followed eventually by burial in a mined geologic repository in the form of unreprocessed spent fuel. The second leading candidate is vitrification in a mixture with high-level radioactive waste from spent fuel, also followed by burial in a repository. The third option is burial in deep boreholes (at depths much greater than that of a mined geologic repository - e.g., $4 \mathrm{~km}$ ).

It is the first leading option that is of interest here: using plutonium in nuclear reactor fuel, so that the plutonium remaining at the end of the fuel cycle is an integral part of spent reactor fuel. Although this approach would not transform all the plutonium into fission products, the plutonium remaining in the spent fuel would be difficult to extract for the manufacture of fission weapons because of the intense radiation emitted by fission products contained in the spent fuel. (However, the decrease of this radiation over several decades is the principal reason that the Academy urges better protection for spent fuel in the long run.)

In the United States, all the reactors suitable for the first leading option are light water reactors (LWRs) that burn uranium fuel in the form of uranium oxide $\left(\mathrm{UO}_{2}\right)$ ceramic pellets. For plutonium disposition, the $\mathrm{UO}_{2}$ would be mixed with plutonium oxide $\left(\mathrm{PuO}_{2}\right)$ to form "mixed-oxide" (MOX) fuel. Most LWRs in the U. S. are believed to be able to operate without modification with a 1/3-core loading of $\mathrm{MOX}$ (in which the $\mathrm{PuO}_{2}$ content is as high as $7 \%$ by weight). Three operating reactors and one unfinished reactor in the U. S. (the Combustion Engineering System-80 models) were designed to operate with a full-core MOX fuel loading. However, none of the U. S. reactors, including the System-80s, are currently licensed to burn any MOX fuel.

The Academy presents a list of major unresolved issues that must be addressed before a program to dispose of weapons-grade plutonium in LWRs can begin in the U. S. Among the key technical issues on this list, some will require a reactor testing program for resolution. Resolution of these issues can essentially be characterized as demonstrating, with sufficient assurance to gain public support and to obtain licensing from the Nuclear Regulatory Commission, that LWRs can be operated safely with MOX fuel. It is important to realize that an operating reactor must undergo a new licensing review fully as stringent as its initial licensing review before it can receive NRC approval to operate with MOX fuel. The application to license operation with MOX fuel must be amply supported by experimental data.

Before a commercial reactor can be licensed to operate with MOX fuel, numerous tests must be performed to obtain the required experimental data. In the next section, the issues that can be resolved by test irradiation of MOX fuel are identified and discussed. Section 3 addresses the suitability of the Advanced Test Reactor (ATR) for performing these tests. Section 4 presents a synopsis of the process one must follow to install and conduct a test in a 
loop facility of the ATR. Section 5 describes the facilities of Argonne National LaboratoryWest (ANL-W) that can support the suggested test program in the ATR. 


\subsection{ISSUES TO BE RESOLVED BY MOX FUEL IRRADIATION TESTING}

All of the specific requirements for MOX fuel testing can be subsumed into one broad requirement: In each type of reactor selected for plutonium disposition, MOX fuel must be shown to function without compromising the safety of operation. As stated in Section 1.0, the operating license of a selected reactor must be amended by the Nuclear Regulatory Commission before the reactor can be operated with MOX fuel. To receive licensing approval for use in a commercial reactor, MOX fuel rods must be shown capable of withstanding a specified level of burnup (expected to be approximately $35 \mathrm{GWd}$ per metric ton of heavy metal (MTHM)) without losing structural integrity or releasing fission product gases through the cladding. This capability must be demonstrated by a test irradiation program. After irradiation, fuel samples will be subjected to various kinds of physical examination, including visual inspection, ceramography, electron microscopy, and chemical analysis.

Also, before a commercial reactor can be licensed to operate with a partial core loading of MOX fuel, the compatibility of MOX fuel assemblies and urania (uranium oxide ceramic) fuel assemblies must be demonstrated. Incompatibility can potentially arise from the different neutronic properties of MOX and urania, as explained below. Although MOX fuels have been used extensively for partial core loading in Europe, where plutonium bred from uranium in LWRs is regarded as an energy resource to be recycled into new fuel assemblies, the European MOX fuel contains reactor-grade plutonium, and therefore it has an isotopic composition different from that of MOX fuel made from weapons-grade material. Furthermore, the plutonia (plutonium oxide ceramic) content of the European MOX fuel is lower - only about $4 \%$ by weight. Therefore, MOX fuel assemblies made from weaponsgrade plutonium, and containing as much as $7 \%$ plutonia, cannot be shown to perform acceptably or to be compatible with urania fuel assemblies solely on the basis of the European experience.

It is recognized by reactor vendors ${ }^{2,3}$ that experimental irradiations of special MOX fuel assemblies, called "Lead Test Assemblies" (LTAs), must take place in commercial reactors of a given type before they can be licensed for extensive use of MOX fuel. Because only a very small portion of the core would be occupied by the LTAs, these experiments could be completed without significantly perturbing the core neutronic or thermohydraulic behavior; hence, these experiments could be performed under a special waiver of normal licensing requirements. Even for an LTA irradiation program, the safeguards concern of using weapons-grade plutonium in commercial reactors must be addressed.

However, even before the irradiation of LTAs in commercial reactors, a great deal of useful testing could be done in a test reactor such as the ATR. In subsequent paragraphs, specific issues are discussed that must be resolved before a commercial reactor can be licensed to operate with MOX fuel. Many of these issues can be resolved more economically in a test reactor than by using LTAs in a commercial reactor. Other issues could not be resolved at all in a commercial reactor. Table 1 lists the issues and indicates whether they could be tested in the ATR and in a commercial reactor. More detailed discussions of the ability of commercial reactors and the ATR to address these issues are presented in Section 3. 
Table 1. Issues and Appropriate Test Facility for MOX Fuel Qualification

Issue Commercial Reactor

Test Reactor

MOX fuel fabrication process verification

Burnable poisons

Effect of low Pu-240 content

Effect of high plutonium content

Americium and gallium content

Fission gas release

Fuel/cladding gap closure

Effects of power cycles on fuel integrity

Off-normal events

Radial distribution of burnup and fission products

Thermohydraulic behavior

Power spiking

Code validation

$\begin{array}{ll}\text { Yes } & \text { Yes } \\ \text { Partially } & \text { Yes } \\ \text { Yes } & \text { Yes } \\ \text { Yes } & \text { Yes } \\ \text { Yes } & \text { Yes } \\ \text { Yes } & \text { Yes } \\ \text { Yes } & \text { Yes } \\ \text { No } & \text { Yes } \\ \text { No } & \text { Yes } \\ \text { Partially } & \text { Yes } \\ \text { No } & \text { Yes } \\ \text { Yes } & \text { No } \\ \text { Yes } & \text { Yes }\end{array}$

The full test program for MOX fuel, including the test-reactor and LTA phases, should address the following issues. Some of the issues are interrelated.

\subsection{MOX Fuel Fabrication Process Verification}

Fuel performance may be expected to depend significantly on the details of the fuel fabrication process. The plutonia may be produced by the oxidation of plutonium metal and calcination of the oxide. The particle size distribution and the effective surface area of the resulting $\mathrm{PuO}_{2}$ powder will not be controlled during this oxidation process; these properties will have to be altered by milling to optimize the sinterability of the urania-plutonia powder mixture and the plutonium homogeneity in the sintered pellets. Pre- and post-irradiation examination of MOX fuel pellets can help correlate the performance parameters with features that depend on the fabrication process. Pre-irradiation examination is necessary to ensure that the pellets are fabricated as intended. Post-irradiation examination is required to determine how performance changes as the as-fabricated features vary. Physical characteristics that depend on the fabrication process and affect fuel performance include fuel homogeneity, fuel porosity, density and stability, stoichiometry, plutonia content, sintering schedules and temperatures, grain size, and others. It is expected that an iterative process will be needed as measured performance parameters guide the selection of process specifications to achieve optimum performance. ATR testing can be used to help select and qualify the fuel rod manufacturing process.

Specific kinds of post-irradiation examinations that will be required are discussed in Section 5. 


\subsection{Burnable Poisons}

The thermal neutron fission cross sections of Pu-239 and Pu-241 are higher than that of U-235. Also, the average number of neutrons released in a fission reaction is higher for plutonium fission than for uranium fission. Therefore, until some of the plutonium initially in the MOX fuel pellets is consumed, the thermal neutron flux in the MOX fuel must be somehow depressed to prevent excessive power density in these pellets. The natural way to achieve this goal is to include burnable poisons in the MOX pellets, either as a mixture in the pellets or as a coating on them (e.g., the Westinghouse IFBA (Integrated Fuel Burnable Absorber) boron coating). Erbium and gadolinium have been proposed for this purpose by U.S. reactor vendors ${ }^{3,4}$. European reactor vendors do not use erbium or gadolinium with MOX fuel, so little if any experience exists for judging their use in this application. The selected burnable poison technique must be demonstrated to work as intended, and the material compatibility of the burnable absorber with the MOX fuel pellet and cladding must be determined.

\subsection{Effect of Low Pu-240 Content}

Reactor-grade plutonium, which accumulates in a light-water reactor by the transmutation of U-238 in a thermal neutron spectrum, contains a higher isotopic percentage of Pu-240 than does weapons-grade plutonium. The thermal fission cross section of $\mathrm{Pu}-240$ is minuscule and its thermal capture cross section is high; thus, the presence of this isotope makes reactor-grade plutonium significantly less reactive than weapons-grade plutonium. All of the European experience with MOX fuel in commercial reactors has been based on reactor-grade plutonium. Therefore, the differences in reactor behavior and in post-irradiation fuel morphology caused by the differing Pu-240 content in reactor-grade and weapons-grade MOX must be understood before the European experience can be transferred to the weaponsgrade plutonium disposal program.

\subsection{Effect of High Plutonium Content}

In the MOX-fueled European commercial reactors, the maximum plutonia content of the MOX fuel pellets $\left(\mathrm{PuO}_{2}\right.$ as a fraction of the total mixed oxide) has been around $4 \%$ by weight. It is expected that MOX fuel pellets developed for plutonium disposal will have up to $7 \%$ plutonia. The effects of the increased plutonium content must be understood. It is unlikely that LTAs with plutonia contents representative of the full MOX core can be designed and approved for operation in existing commercial plants. To demonstrate the inreactor behavior of MOX fuel with the full expected plutonia content, and to achieve bounding power histories, short rods (equal in length to the ATR core height) should be irradiated in the ATR. 


\subsection{Americium and Gallium Content}

The weapons-grade plutonium removed from warheads contains significant quantities of americium, which is a strong gamma-ray emitter. Americium tends to be released during the sintering process by which the MOX pellets will be made. This release creates a contamination hazard for workers. In the development of the pellet fabrication process, an assessment will be made of the need to remove americium and of the difficulty of doing so. Weapons-grade plutonium also contains about $1 \%$ gallium by weight to enhance the stability of the weapon pit. The gallium may be retained in the MOX fuel or removed, depending on the pit-metal-to-oxide conversion process. If gallium is not removed during oxide conversion, gallium oxide could affect the homogeneity or the hot-pressing characteristics of the plutonium oxide powder. ${ }^{5}$ Testing must be performed to ensure that the gallium impurity does not embrittle the cladding during irradiation.

If americium and gallium are removed, then a significant waste-disposal problem will be created.

\subsection{Fission Gas Release}

As fission burnup proceeds, gaseous fission products tend to migrate to grain boundaries in the pellet, then to the pellet surface, and finally on into the gap between the pellet and cladding. Buildup of fission gas in the gap causes an increase in the pressure inside the cladding tube. In order to be sure of the integrity of the cladding, this pressure must be known quantitatively. Some of the European experience suggests that the fission gas pressure may be greater for MOX fuel than for urania fuel. ${ }^{6}$ The ATR can be used to confirm thermal-mechanical parameters such as fission gas release, swelling, and pore distribution.

\subsection{Fuel/Cladding Gap Closure}

As materials undergo irradiation, they change dimensionally by such processes as creep and swelling. Therefore, the gap between the fuel pellet surface and the cladding inner surface will change over time. Clearly, the course of this change will depend on the cladding material as well as on the pellet material. A Westinghouse study raises a concern that excessive departure from nucleate boiling can occur if the gap closes because the pellet and cladding swell at different rates. ${ }^{2}$ Evidently, this concern is based on the possibility that sudden gap closure would allow the stored-up heat in the pellet to flow out through the cladding rapidly and dry out the cladding outer surface. This dryout could lead to cladding failure. 


\subsection{Effects of Power Cycles on Fuel Integrity}

In commercial reactors, fuel changeout is done in stages. Only about a third of the fuel in a commercial reactor core is removed during each refueling outage; the rest is relocated in the core to allow its residual fissile material to be used to its potential. Thus, MOX fuel assemblies would normally remain in the reactor through two shutdowns. Also, the operating power level is subject to some fluctuation, even though nuclear power plants are ordinarily operated as base-load facilities. Because of these changing power levels, the fuel pellets heat and cool repeatedly. Since the thermal conductivities of ceramic materials such as plutonia are low, these materials can develop very high thermal stresses during heating and cooling. The consequences of fluctuating pellet temperatures for pellet structural integrity should be investigated.

\subsection{Off-Normal Events}

Operating nuclear power plants are licensed only after extensive analysis of their response to a variety of hypothetical "off-normal events" - i.e., events that are thought to have potential to cause accidents. Examples of such events that could be simulated in the ATR are power ramps, overpower excursions, and coolant flow coastdowns. It must be shown that the change in fuel form from urania to MOX does not threaten the favorable outcome of such off-normal event scenarios. Many off-normal events can be simulated in a test reactor by changing the thermohydraulic conditions and the operating power in the test location. The ATR can be used to generate data for off-normal conditions as required by the Nuclear Regulatory Commission.

\subsection{Radial Distribution of Burnup and Fission Products}

In order to validate fuel performance codes, which predict in detail the radial distribution of burnup and fission product accumulation, the fuel development team must determine the actual radial dependency of post-irradiation composition by destructive examination of irradiated pellets.

\subsection{Thermohydraulic Behavior}

Heat transfer characteristics of MOX fuel rods will be different from those of urania fuel rods operating in the same neutronic and thermohydraulic environment. This will be especially true if stainless steel is chosen as the cladding material for MOX fuel. MOX fuel must be shown to release fission heat into the coolant without exceeding temperature limits or departing from safe, stable heat transfer regimes. 


\subsection{Power Spiking}

Because MOX fuel has higher average fission cross sections and fission neutron yields than does urania fuel, the outermost fuel rods in a MOX fuel assembly would tend to produce a higher power density than the adjacent urania fuel assemblies if the fissile content were the same in the MOX and urania regions. Then the higher neutron absorption in these outer fuel rods would tend to shield the inner rods in the MOX assembly, leading to lower power density in the inner region. To prevent this "power spiking" in the outer MOX rods, the fissile content in these outer rods should be reduced. The very outermost layer of fuel rods in the assembly would have a plutonia content as low as about $2 \%$, and the plutonia content of rods located deeper in the assembly would be graduated to a maximum of about $7 \%$. Testing is needed to determine the level of power peaking and its impact on the performance of the fuel.

\subsection{Code Validation}

Sophisticated computer codes are used in every stage of nuclear power plant fuel cycle planning and operation. These codes must be benchmarked for the actual conditions encountered in each reactor. In preparing to load a commercial reactor with MOX fuel made from weapons-grade plutonium, a great deal of preliminary benchmarking must be done. Fuel performance codes, in particular, can be benchmarked by data obtained from testing in the ATR. 


\subsection{THE POTENTIAL ROLE OF THE ATR IN MOX FUEL TESTING}

To be suitable for effective testing of nuclear fuel, a test reactor should possess several desirable qualities. It should have large test space capacity in and around the core, high neutron flux, a wide latitude of experiment parameter control, extensive instrumentation facilities, and a regular operating schedule. It should be supported by a wide range of facilities for handling and examining irradiated test specimens, and it should be staffed and supported by personnel with a broad range of technical expertise for experiment planning and analysis. Because the ATR was designed specifically for fuel testing, and because it has performed this mission for nearly thirty years, it possesses all of these qualities to a greater extent than any other test reactor in the world.

Because it is a fuel-testing reactor by design, the ATR has the capability to address most of the issues identified in Section 2. The ATR can perform the irradiations needed to confirm the process and product qualifications for the fuel fabrication process and products, and to generate data for off-normal conditions as required by the Nuclear Regulatory Commission. The ATR test loops are large enough to accommodate a $5 \times 5$ subassembly of partial-length (1.22-m (4-ft.)) pressurized-water-reactor fuel rods. (Rods for boiling-water reactors are larger, so fewer of them could be accommodated in the ATR - for the Advanced BWR, a $4 \times 4$ array.) For some of the issues, the ATR is almost ideally suited, while commercial reactors are not suitable at all. Only for one of the issues - power spiking - is the ATR unsuitable, but no other test reactor would be any better; for this issue, LTA irradiations will be necessary. The use of ATR should minimize the safeguards concern that would arise with the irradiation of MOX LTAs in a commercial reactor.

Two distinct types of tests can be performed in the ATR. One of these types entails testing in loops, or in-pile tubes. In loop tests, the irradiation targets are placed in a test space that is provided with its own coolant supply at pressure and temperature controlled independently from the reactor core coolant. Four loop facilities are currently available; all of them are relatively large spaces, but one (the Large In-Pile Tube) is especially large, with a test space diameter of $13.65 \mathrm{~cm}$. These loops are closely surrounded by fuel assemblies and offer high neutron flux levels (about $10^{15}$ neutrons $/ \mathrm{cm}^{2}-\mathrm{s}$ of total flux). The other type of test is the drop-in capsule test. In this type of test, the test space is cooled by primary cooling-system water that is separated from the core coolant in the core inlet plenum and rejoined with the core coolant in the core outlet plenum. A large variety of drop-in capsule locations is available. Those in high-flux locations near fuel assemblies are relatively small, but some very large ones (up to $12.7 \mathrm{~cm}$ in diameter) are available in low-flux locations farther from the core.

Since the MOX testing program would generally require high neutron fluxes, drop-in capsule tests would be most appropriate for irradiation of small specimens such as single fuel rods or even individual pellets. The loop tests would best be reserved for tests of rod arrays, or for tests involving modulation of coolant flow.

In order for testing in a test reactor to be relevant to the ultimate commercial reactor environment, the neutron energy spectrum in the test space must be close to the spectrum the 
MOX fuel assemblies would encounter in the commercial reactor. Preliminary calculations ${ }^{7}$ using the code MCNP indicate that an appropriate amount of hafnium shielding around the test space in an in-pile tube could produce a spectrum in the ATR that matches the MOX-fuel commercial reactor spectrum very closely. Hafnium shrouds in drop-in capsule locations have been shown able to partially adjust the ATR spectrum to conform to the anticipated MOX-fuel commercial reactor spectrum, but further refinements would be desirable.

As noted above, it appears that the ATR can deliver a neutron spectrum in the test loop location that would be very representative of the spectrum a MOX fuel assembly would encounter in a commercial reactor. ${ }^{7}$ Commercial reactors with LTAs may not have neutron spectra representative of that in a full MOX or $1 / 3-\mathrm{MOX}$ core. Beyond this basic requirement, the ATR has outstanding flexibility for performing a MOX fuel test program. Some of the ATR's capabilities could allow testing on an accelerated schedule. The neutron flux level can be kept considerably higher than that in a commercial reactor, ${ }^{8}$ so that the required burnup level can be reached more quickly. Loop flow velocity can be modulated arbitrarily, so that off-normal conditions can be simulated at will. The short duration of the typical ATR cycle (about 40 days) will produce frequent power cycles. The ATR's Powered Axial Locator Mechanism (PALM) test facility can impose even more rapid power fluctuations on the test fuel. Such tests could not be performed in a commercial reactor.

Obviously, it would be highly detrimental to the mission of a commercial reactor to shut it down between scheduled refueling outages to remove LTAs for assessment; therefore, access to the LTAs would be unavailable except during these scheduled shutdown events. Therefore, examination of MOX fuel at shorter intervals would be impractical in a commercial-reactor testing program. Typically, refueling outages occur annually in a commercial reactor. However, the erbium and gadolinium materials contemplated for use as burnable poisons would be consumed in less than a year in a commercial reactor radiation environment. In the ATR, MOX fuel elements could be removed at much shorter intervals. Some ATR cycles are planned to last only a week or two. Thus, testing in the ATR would allow determination of the time-dependency of the burnable poison content.

Similarly, frequent access to MOX fuel rods in an ATR test program would allow frequent examination of MOX fuel for studying the time-dependency of fission gas release, pellet/cladding gap distance, neutron fluence, and the radial distribution of burnup and fission products.

Issues that could be treated as well in the ATR as in the LTA program include the effect of the Pu-240 level and the behavior of pellets with full expected plutonia content. Resolution of the issue of whether or not to extract americium before pellet fabrication is independent of where the test irradiations take place. Experiences with handling MOX containing americium could be gained in an ATR test program.

Resolving the issue of power spiking is likely to require tests with a full-size MOX fuel assembly located among urania assemblies. Although a commercial reactor would be required to study this phenomenon, the INEL is very capable of supporting studies of power spiking by performing computer calculations using Monte Carlo techniques. However, the 
ATR test program is not intended to replace the LTA program, which is an indispensable part of the MOX fuel licensing process. Instead, the test reactor program can provide otherwise unobtainable test data, identify potential fuel performance problems early in the fuel development program, and build confidence for a successful and less costly LTA program. It can shorten and complement the LTA program, provide better data for the resolution of many issues, and address some issues for which the LTA program is not suited at all.

The ATR is supported by a wide variety of facilities and experienced personnel for all types of post-irradiation handling and examination. The INEL has a variety of hot cell facilities. Also, the facilities at Argonne National Laboratory-West (ANL-W) are located on the grounds of the INEL; ANL-W has vast experience in handling plutonium (in forms appropriate for the fabrication, use, and recycling of metallic fuel). These facilities at ANL-W are discussed in detail in Section 5. 


\subsection{CONDUCTING A TEST PROGRAM IN ATR LOOP AND CAPSULE FACILITIES}

Before a test can be installed in the ATR, it must be shown to be compatible with the design and operational constraints on the reactor. The test hardware must fit geometrically into a test space that can provide the required neutron flux. The materials used in the test must be compatible with the reactor materials. The thermohydraulic environment in the test locations must be suitable for successful completion of the test. The scheduling requirements for the test must fit with the scheduling commitments that have been made for the reactor to conduct other test programs. Most important of all, the test hardware and the test program must not compromise the operational safety of the reactor. These considerations are discussed in more detail below.

\subsection{Description of Test Hardware}

A complete description of the test-specific hardware must be provided to ATR operations personnel. This description must include drawings of all components, showing dimensions and specifying materials.

\subsection{Specification of Requirements for Operating Conditions}

ATR operations personnel must be informed of all the constraints on operating conditions that are required to obtain meaningful data from the test program. Examples of such constraints are given below:

- $\quad$ Reactor power

- Coolant temperature, pressure, and flow rate

- Coolant chemistry requirements

- Neutron flux and fluence

- $\quad$ Requirement for use of Powered Axial Locator Mechanism (PALM)

- Requirement for installation in Standard or Large In-Pile Tube (SIPT or LIPT)

- Specification of all parameters that must be measured or controlled. 
The requirements for performing the test will be reviewed against the requirements of the ATR Technical Specifications to ensure that the limits imposed by the Technical Specifications are not violated. This review will be performed by the ATR operations technical staff.

\subsection{Scheduling Requirements}

A time window should be provided to ATR operations personnel so that the test can be conducted during a time interval when the required test location is available. The detailed test specifications must be provided at least six weeks before the start of the test, in order to allow the test characteristics to be represented in a Core Safety Assurance Package (CSAP).

\subsection{Safety Considerations}

The CSAP calculations ensure adequate reactivity margins in normal operating conditions. Assurance must also be given that off-normal events do not create conditions that exceed the operating limitations of the reactor. One way to provide this assurance is to show that the consequences of all plausible events are bounded by the consequences of acceptable events that have already been analyzed. The other way to provide the required assurance is to perform the appropriate analyses. Events that must be considered include the following:

- Loss of hafnium shroud from around the MOX fuel rods

- $\quad$ Meiting of MOX fuel rods and release of fissile material into the loop coolant

- Reactor coolant and test loop coolant flow coastdown events

- Loss of coolant events

- Events involving loss of temperature control or loss of heat sink.

Also, it will be necessary to determine the margins to critical heat flux (CHF) and flow instability in normal operating conditions. Adequate lead time will have to be provided for analysis of these off-normal events. In general, such analyses can be expected to take several man-months. To perform these analyses, the temperature and void coefficients of reactivity will have to be determined.

The Updated Final Safety Analysis Report would have to be modified if any events were shown to have consequences not bounded by previous analyses. 


\subsection{POST-IRRADIATION EXAMINATION CAPABILITIES AT ANL-W}

The Hot Fuel Examination Facility (HFEF), at Argonne National Laboratory-West on the INEL, is a large alpha-gamma hot cell facility which was designed to characterize highly irradiated fuel and structural materials by remote handling. The wide range of fuel handling and measurement capabilities at HFEF, coupled with ANL-W's experience in testing and analyzing fuel behavior, makes HFEF an ideal facility in which to carry out MOX fuel characterization activities.

The kinds of nondestructive and destructive examinations that will need to be performed on irradiated specimens in a MOX fuel qualification program are discussed below. Then the specific examination capabilities available in HFEF are described.

\subsection{Non-destructive examinations}

\section{Visual Examination}

Although gross deviations of the performance of MOX fuel from that of urania fuel are not expected, MOX fuel rods tested in the MOX qualification program should be visually examined. Photographs should be taken to document the occurrence or absence of any unusual features or obvious cladding degradation observed during the visual examination.

\section{Weight Measurement}

Measurements of the weight of a fuel rod can often help in the identification of breached fuel rods that have failed by very small cracks that may not be seen during the visual examination. Therefore, the intact irradiated fuel rods should be weighed.

\section{Cladding Dimensional Measurements}

Differences in linear heat generation rates between MOX and urania fuel rods will influence cladding mechanical behavior. Cladding profilometry measurements should be made to quantify rod length change, rod bowing, cladding ovality, and cladding diameter as functions of axial position, in order to identify and evaluate cladding creepdown, pellet interface ridging, and pellet-cladding mechanical interaction.

\section{Neutron Radiography}

Fuel column length change, or axial growth, affects core reactivity and can place axial stresses on the cladding following pellet-cladding contact; conversely, pellet-cladding mechanical interaction can restrain fuel growth. Fuel axial growth should be identified by neutron radiography of the intact irradiated fuel rods. Neutron radiography of the fuel column will also reveal longitudinal fuel cracking patterns. 


\section{Gamma Spectroscopy}

Axial gamma scanning and spectral analysis are needed to confirm that there is no unexpected migration of fission products or burnable poisons within the fuel rod. Information on interactions between pellets will also be revealed by axial gamma scans. These scans will confirm power and burnup profiles in the fuel rods. Finally, gamma scanning can be used as another means of checking for cladding breach.

\subsection{Destructive Examinations}

\section{Plenum Gas Pressure and Volume Analysis}

It is important to understand fission gas release by MOX fuels in order to quantify the internal pressurization rate in the fuel rods. By puncturing the fuel rods and collecting the plenum gas into a known volume at a reference temperature, one can determine the quantity of gas released to the plenum. Then a sample of this gas can be analyzed isotopically to determine its chemical makeup. Repressurization of the fuel rod using a known amount of gas will yield the free volume within the rod, allowing the internal pressure of the intact irradiated fuel rod to be inferred.

\section{Microstructural Evaluation}

It will be necessary to quantify the chemical and microstructural evolution of the fuel and cladding in order to evaluate the radial migration of fuel constituents, burnable poisons, and fission products, and to determine the microstructure and porosity distributions and the extent and type of pellet-cladding chemical interactions. These goals can be accomplished by sectioning the fuel rods transversely, and possibly longitudinally, and examining the cladding, the fuel, and the fuel-cladding interface by optical and/or electron microscopy. Electron microprobe analysis will yield radial distributions of fuel constituents, burnable poisons, and fission products. During the sectioning process, fuel samples can be taken for analytical chemistry analyses to determine burnup, irradiated fuel density, and retention of fission gas.

\subsection{Examination capabilities in HFEF}

HFEF is composed of a shielded main cell, where the characterization work is performed, and a connected shielded air cell that houses aqueous decontamination facilities. The main cell has an inert argon atmosphere (maintained at less than $100 \mathrm{ppm}$ oxygen and water vapor) that protects exposed fuel constituents from air/moisture reactions and suppresses fires. The main cell has 15 work stations, each equipped with its own pair of master-slave

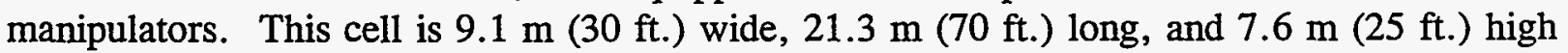
inside. Components up to $9.1 \mathrm{~m}$ tall can be transferred into the cell by a roof bay. Casks up to $45 \mathrm{Mg}$ (50 tons) can be handled. HFEF possesses the following characterization capabilities. 


\section{Physical Condition of Irradiated Fuel}

HFEF personnel routinely measure and document the general physical condition of irradiated fuel and other materials. At the Vertical Assembly/Dismantling Machine (VAD), engineers record and macro-photograph all unusual features, including corrosion deposits, mechanical damage, warpage, bulges, breach sites, etc. Higher-magnification stereo photography at precisely-known locations on individual fuel rods are routinely made at the Visual Examination Machine (VEM). Corrosion deposits can be sampled and quickly transferred to the Analytical Laboratory for assay, and suspicious areas can be smeared for the presence of fuel particulate matter or fission products.

\section{Metrology}

For the case of cylindrical fuel rods, diameter data are collected at the Element Contact Profilometer (ECP). This computer-automated apparatus determines the diameter of fuel rods up to $21 \mathrm{~mm}$ in diameter with an accuracy of $\pm 0.008 \mathrm{~mm}$. The amount of fuel rod bowing and the fuel rod length are measured optically at this same station.

An in-cell balance is provided, which can weigh fuel elements up to $4 \mathrm{~kg}$ in mass. Weight

- measurements are often useful in identifying breached fuel elements that have very small cracks or pits which are difficult to observe visually.

\section{Gas Sampling and Analysis}

For fuel rods that contain a fission gas plenum, the Gas Assay Sample and Recharge (GASR) apparatus is invaluable. The plenum free volume, gas pressure, and molar quantity can be determined by laser-puncturing and calibrated gas collection hardware. Samples of the gas are taken and transferred to the Analytical Laboratory for the determination of their chemical and iśotopic composition.

\section{Neutron Radiography}

The Neutron Radiography (NRAD) facility within HFEF uses a $250 \mathrm{~kW}$ TRIGA reactor as a neutron source. Round components up to $152 \mathrm{~mm}$ in diameter or square components up to $241 \mathrm{~mm}$ across, and weighing up to $273 \mathrm{~kg}$, can be radiographed. Neutron radiography is a powerful tool for detecting such fuel heterogeneities as pellet separations, cracks, fission product relocation, etc. Indium and dysprosium are used as neutron detector foils for highenrichment fuels (and thick structures) and for low-enrichment fuels (and thin structures), respectively. Neutron tomography can be performed if detailed three-dimensional imaging is required. 


\section{Fission/Activation Product Data}

Fission and activation product spatial distributions in irradiated fuel can be determined using HFEF's automated Precision Gamma Scanner. Such data have been found useful in locating cladding breach sites and as a complement to quantitative assays made at the Analytical Laboratory.

Microstructural Evaluation

A detailed microstructural evaluation is often necessary for understanding and modeling of fuel degradation mechanisms. HFEF has a shielded auxiliary cell for optical and scanning electron microscopy. A microhardness tester is also available to ascertain mechanical property degradation. Should the need arise, samples can be shipped to the Alpha-Gamma Hot Cell Facility (AGHCF) in Illinois, where electron microprobe and scanning Auger microscopy capabilities exist. 


\section{REFERENCES}

1. National Academy of Sciences, Committee on International Security and Arms Control, Management and Disposition of Excess Weapons Plutonium, National Academy Press, 1994.

2. "Plutonium Disposition Study, Phase II Final Report, Volume I," DOE/SF/19683-5, Westinghouse Electric Corp., p. 2.1-69, April 30, 1994.

3. "Study of Plutonium Disposition Using Existing GE Advanced Boiling Water Reactors," NEDO-32361, GE Nuclear Energy, June 1, 1994.

4. Combustion Engineering, Inc., "Plutonium Disposition Study - Technology Needs," 457-3.wp2(J:9341).

5. G. A. Armantrout et al., "Recovery of Weapon Plutonium as Feed Material for Reactor Fuel," UCRL-ID-117010, Lawrence Livermore National Laboratory (1994).

6. A. Boltax, "Mixed Oxide Fuel for a Plutonium Disposition Reactor (PDR600) - A Review of Fuel Technology," DOE/SF/19683-3, Westinghouse Electric Corp., p. 312, March 15, 1994.

7. J. W. Sterbentz, J. M. Ryskamp, S. C. Mason, and G. S. Chang, "Mixed Oxide Fuels Testing in the Advanced Test Reactor," Trans. Am. Nucl. Soc., 71, 301 (1994).

8. J. M. Ryskamp, J. E. Connor, and F. W. Ingram, "The Potential for New Societal Contributions from the Advanced Test Reactor," Trans. Am. Nucl. Soc., 모, 159 (1993). 